\title{
The effects of naloxone on hoarding in the Syrian hamster (Mesocricetus auratus)
}

\author{
MICAELA URBANO and RALPH G. NOBLE \\ Rensselaer Polytechnic Institute, Troy, New York 12181
}

\begin{abstract}
The effects of the opiate antagonist naloxone on the hoarding behavior of intact female hamsters, Mesocricetus auratus, were studied. Naloxone reduced the number of food pellets hoarded $(p<.01)$ but did not affect the initiation of hoarding behavior. Further analysis indicated consistent individual differences in the effect of naloxone administration on hoarding $(p<.05)$.
\end{abstract}

The endorphins have been implicated in a wide range of behavioral systems (Goldstein, 1978). With the apparent exception of sexual behavior (Ostrowski, Stapleton, Noble, \& Reid, 1979), opiate antagonists mildly suppress appetitive behaviors and opiate agonists facilitate appetitive behaviors at low doses and inhibit behavior at high doses (Noble, Note 1). The consistency of these effects suggests that the endorphins act on appetitive behaviors, at least in part, via a common mechanism.

The search for this putative mechanism of action is complicated by the widespread distribution of the endorphin system, the large number of endogenous ligands, and the apparent multiplicity of opiate receptors (Guillemin, Ling, Lazarus, Bungus, Minicks, Bloom, Nicoll, Siggins, \& Gegal, 1977). Opiate receptors have been located throughout the nervous system and in several peripheral organs involved in ingestion and reproduction (Guillemin et al., 1977; Murphy, Bowie, $\&$ Pert, 1979). The relative importance of central and peripheral sites of action in the modulation of appetitive behaviors by the endorphin system has not been clearly established.

Hoarding does not produce the complex pattern of physiological changes produced by feeding and drinking and is insensitive to short-term changes in the nutritional status (Herberg \& Blundell, 1970; Morgan, Stellar, \& Johnson, 1943; Noble, Note 2). Hoarding can be readily studied in hamsters that have not been food deprived (Estep, Lanier, \& Dewsbury, 1978), which is important, since there is evidence that food deprivation may activate the endorphin system (McGiven \& Berntson, 1980).

This experiment evaluated the effects of the opiate antagonist naloxone on hoarding behavior of female hamsters. Because there are consistent individual differences in the hoarding behavior of hamsters (Davidson, Vicente, \& Noble, Note 3), we designed the experiment to evaluate possible individual differences in responsiveness of hoarding behavior to naloxone administration.

This research was supported by NSF Grant BNS78-17860. The naloxone used was a gift from ENDO Laboratories.

\section{METHOD}

\section{Subjects}

Twelve intact female hamsters were used in this experiment. The hamsters had been purchased from Engle's Laboratory Animals, Inc., at 60 days of age and were approximately 6 months old at the time of testing. The animals were housed four per cage in solid bottom plastic cages $(38 \times 33 \times 17 \mathrm{~cm})$ on arrival in the animal colony, which was maintained at $22^{\circ} \mathrm{C}$ on a reversed light cycle (light: dark $=14: 10 \mathrm{~h}$ ) with the onset of the dark phase of the light:dark cycle at $1400 \mathrm{~h}$. Purina Rat Chow and tap water were continuously available. The corn cob bedding was changed weekly. Females were individually housed 1 week before the start of testing and were maintained in individual cages throughout the experiment.

\section{Design}

All females were given three preliminary hoarding trials to familiarize them with the procedure. Three weeks later, all females were tested for hoarding behavior on 4 consecutive days (Phase 1) to determine if the small but significant changes in hoarding behavior over the estrous cycle reported by Estep et al. (1978) would occur in our testing procedure. Estrous cycles were determined by monitoring the vaginal discharge (Orsini, 1961).

Then, in Phase 2, the females were tested for hoarding behavior four times, twice following the administration of naloxone and twice following the administration of saline. During the 1st week, all the animals were tested on 2 consecutive days. On Day 1, half the animals were tested $10 \mathrm{~min}$ after the administration of naloxone hydrochlorine $(4 \mathrm{mg} / \mathrm{kg}$ administered subcutaneously in physiological saline) and half were tested following the administration of an equal volume/body weight of physiological saline. The animals receiving naloxone on Day 1 received saline on Day 2, and the animals receiving saline on Day 1 received naloxone on Day 2. The next week, the experiment was replicated using the same animals with the order of testing reversed for each animal.

\section{Procedure}

Tests were conducted between $1700-1900 \mathrm{~h}$, about $3 \mathrm{~h}$ after the onset of the dark phase of the light:dark cycle. Tests were $15 \mathrm{~min}$ long and were conducted with the females in their home cages. Food pellets were presented to the animals by inserting them between the bars of the cage lid so that approximately half of the pellet protruded into the animal's cage. In Phase 1 , 12 food pellets were placed in the cage lid before the start of the test, and the test was terminated when the animal had hoarded all 12 pellets. In Phase 2 , the tests were started with four pellets in the cage lid. As each pellet was removed, another pellet was inserted. The time at which the pellet was removed from the lid was recorded, and only pellets put in a neat pile were scored as having been hoarded. In our procedure, pellets 
removed from the lid are almost invariably hoarded. All pellets were removed from the animal's cage at the start of Phase 1 and at the start of Phase 2, but the animals were allowed to retain the pellets hoarded during each phase, since hoarding behavior is insensitive to the size of the existing hoard (Marx, 1952).

\section{RESULTS}

\section{Phase 1}

There were consistent individual differences in the latency to hoard the first pellet $[F(10,30)=6.25$, $\mathrm{p}<.01]$, in the average interval between pellets hoarded $[F(10,30)=8.46, p<.01]$, and in the total number of pellets hoarded $[F(10,30)=3.86, p<.01]$. There were no significant fluctuations as a function of the estrous cycle. A separate analysis indicated that none of the measures varied significantly across the 4 consecutive days of testing. All measures of hoarding (latency to hoard first pellet, average interresponse interval, and total number of pellets hoarded) were highly correlated (product-moment correlations ranged from .72 to .91; all significant, ps $<.01$ ).

\section{Phase 2}

When subjects was used as a factor in the analysis, there was both a significant overall reduction in hoarding as a result of naloxone administration $[F(11,23)=13.31$, $\mathrm{p}<.01]$ and a significant interaction between subjects and naloxone administration $[\mathrm{F}(11,23)=2.4, \mathrm{p}<.05]$. A separate analysis indicated that neither the effects of repeated testing nor the interaction between naloxone administration and repeated testing was significant. One animal did not hoard under either condition and was not included in further analyses (see Table 1).

Of the 11 animals that did hoard consistently, 7 hoarded less following naloxone injection in both replications, 3 hoarded more following naloxone in both replications, and 1 animal hoarded more following naloxone in the first replication and less following naloxone in the second replication.

The topography of hoarding behavior and the effect of naloxone on hoarding behavior were further analyzed by computing the frequency of different interresponse intervals sorted into bins $10 \mathrm{sec}$ wide (i.e., all intervals less than or equals to $10 \mathrm{sec}$, all intervals greater than $10 \mathrm{sec}$ and less than or equal to $20 \mathrm{sec}$, etc.). The average frequency of different classes of interresponse intervals

Table 1

The Effects of Naloxone on Hoarding in Female Hamsters

\begin{tabular}{lccccc}
\hline & \multicolumn{2}{c}{ Naloxone } & & \multicolumn{2}{c}{ Control } \\
\cline { 2 - 3 } \cline { 5 - 6 } & Mean & SE & & Mean & SE \\
\hline Latency to Hoard (in Seconds)* $^{*} 36.0$ & 8.0 & & 29.0 & 4.0 \\
Number of Pellets Hoarded** & 37.1 & 4.5 & & 27.5 & 5.1 \\
\hline
\end{tabular}

*Data from one animal that did not hoard were deleted from these calculations. ${ }^{* *} F(1,23)=13.31, p<.01$.

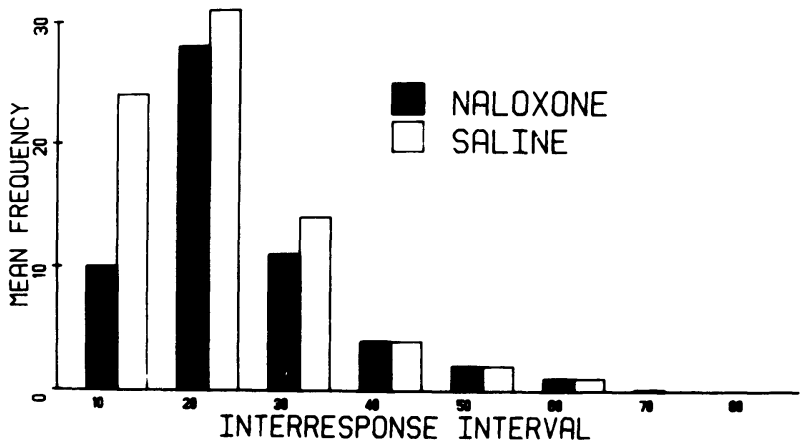

Figure 1. Naloxone administration selectively reduces the frequency of short $(\leqslant 10 \mathrm{sec})$ intervals between hoarding responses.

is summarized in Figure 1. Naloxone administration significantly reduced the frequency of short interresponse intervals $(\leqslant 10 \mathrm{sec})$ in both replications (ps $<.04$, sign test), without significantly altering the frequency of other classes of interresponse intervals (ps $>.05)$. The effect of naloxone on the shortest interresponse intervals was apparently independent of its effect on the overall amount hoarded, since this effect was observed in 10 of the 11 animals that hoarded consistently, including the 3 animals that hoarded more following naloxone administration in both replications.

\section{DISCUSSION}

The overall reduction in hoarding produced by naloxone is consistent with previous reports that naloxone reduces appetitive behaviors (Holtzman, 1979) and adds support to the hypothesis that the endorphin affect many different forms of motivated behavior in a similar fashion. Naloxone also reduced the likelihood that female hamsters would hoard two pellets in quick succession, an effect apparently independent of the effect on the total amount hoarded.

The effects of naloxone on hoarding closely resemble the effects of naloxone on the behavior of rats working for sweetened condensed milk on an FR 50 schedule. Wheeling, Tarika, and Kornetsky (1980) reported that naloxone both increased the duration of postreinforcement pauses and produced an early termination of responding. In the case of hoarding, naloxone decreased the rate of responding by selectively reducing the frequency of very short interresponse intervals. In general, it is not clear how opiate antagonists change the overall rate of responding in appetitive situations. In male hamsters, naloxone reduces the rate at which male hamsters attempt to copulate with females (Noble, Note 1). In male rats, naloxone has been reported to increase the duration of pauses in copulatory behavior that follow ejaculation (Myers \& Baum, 1979; Sach, Valcourt, \& Flagg, 1981). Considering the short half-life of the endorphins (Guillemin et al., 1977), an analysis of the effects of opiate agonists and antagonists on the fine-grained temporal structure of behavior in appetitive situations would seem critical to the understanding of the role of endorphins in motivated behavior.

\section{REFERENCE NOTES}

1. Noble, R. G. Hamster sexual functioning: Modulation by opiate agonists, opiate antagonists, and exercise. Paper presented at the Eastern conference on reproductive behavior, Rockefeller University, New York, 1980. 
2. Noble, R. G. Unpublished observations, 1981.

3. Davidson, J. C., Vicente, I., \& Noble, R. G. Hoarding in hamsters. Paper presented at the 51st annual meeting of the Eastern Psychological Association, Hartford, Conn., 1980.

\section{REFERENCES}

Estep, D. Q., Lanier, D. L., \& Dewsbury, D. A. Variation of food hoarding with the estrus cycle of Syrian golden hamsters (Mesocricetus auratus). Hormones and Behavior, 1978, 11, 259-263.

Goldste In, A. Opiate receptors and opioid peptides: A ten year overview. In M. G. Lipton, S. DiMascio, \& K. F. Killam (Eds.), Psychopharmacology: A generation of progress. New York: Raven Press, 1978.

Guillemin, R., Ling, N., Lazarus, L., Bungus, R., Minicks, S., Bloom, F., Nicoll, R., Siggins, G., \& Gegal, D. The endorphins, novel peptides of brain and hypophyseal origin with opiate-like activity: Biochemical and biological studies. In D. Krieger \& W. G. Ganong (Eds.), ACTH and related peptides. Structure, regulation, and action. New York: Annals of the New York Academy of Science, 1977.

Herberg, L. J., \& Blundell, J. E. Non-interaction of ventromedial and lateral hypothalamic mechanisms in the regulation of feeding and hoarding behavior in the rat. Quarterly Journal of Experimental Psychology, 1970, 22, 133-141.

Holtzman, S. G. Suppression of appetitive behavior in the rat by naloxone: Lack of effect of prior morphine dependence. Life Sciences, 1979, 24, 219-226.

MARX, M. H. Infantile deprivation and adult behavior in the rat:
Retention of increased rate of eating. Journal of Comparative and Physiological Psychology, 1952, 45, 43-49.

McGivern, R. F., \& Berntson, G. G. Mediation of diurnal fluctuations in pain sensitivity in the rat by food intake pattern: Reversal by naloxone. Science, 1980, $210,210-211$.

Morgan, C. T., Stellar, E., \& Johnson, O. Food deprivation and hoarding in rats. Journal of Comparative and Physiological Psychology, 1943, 35, 275-293.

Murphy, M. R., Bowie, R. D. L., \& Pert, C. B. Copulation elevates plasma B-endorphin in the male hamster. Society for the Study of Neurosciences Abstract, 1979, 5, 470.

MYers, B. M., \& BAUM, M. J. Facilitation by opiate antagonists of sexual performance in the male rat. Pharmacology, Biochemistry and Behavior, 1979, 10, 615-618.

Orsini, M. W. The external vaginal phenomena characterizing the stages of the estrous cycle, pregnancy, pseudopregnancy, lactation, and the anestrous hamster, Mesocriecetus auratus waterhouse. Proceedings of the Animal Care Panel, 1961, 11, 193-206.

Ostrowski, N. L., Stapleton, J. M., Noble, R. G., \& Reid, L. D. Morphine and naloxone's effects on sexual behavior of the female golden hamster. Pharmacology, Biochemistry and Behavior, 1979, 11, 673-681.

Sachs, B. D., Valcourt, R. J., \& FlagG, H. C. Copulatory behavior and sexual reflexes of mole rats treated with naloxone. Pharmacology, Biochemistry and Behavior, 1981, 14, 251-253.

Whenling, H. S., TARIKa, J., \& Kornetsky, C. Effects of acute and chronic administration of naloxone on scheduled behavior. Federation Proceedings, 1980, 37, 764.

(Received for publication October 17, 1981.) 